\title{
Analysis of the stress-strain state of a tank in case of irregular subsidence along the periphery
}

\author{
Petr Chepur ${ }^{1}$, Aleksandr Tarasenko ${ }^{1}$, Alesya Gruchenkova, ${ }^{2, *}$, and Youhai Guan ${ }^{3}$ \\ ${ }^{1}$ Industrial University of Tyumen, Volodarskogo Street 38, Tyumen, 625000, Russia \\ ${ }^{2}$ Surgut Oil and Gas Institute, Entuziastov Street 38, Surgut, 628405, Russia \\ ${ }^{3}$ China University of petroleum, 266580 Qingdao Shandong, China
}

\begin{abstract}
In the article, the authors proposed a calculation model for determining the SSS of a vertical steel tank in case of irregular subsidence of the external bottom contour in accordance with the geometric parameters of a real RVS-20000 $\mathrm{m}^{3}$ tank. An experiment is planned and presented including a scheme with two influencing factors: the geometric model of the tank and the value of the dimensionless coefficient $\mathrm{m}$. The influencing factors have 3 and 5 combinations respectively, which is represented in the experiment matrix. The article shows diagrams of displacements, stresses of the tank structures, and graphically depicts the dependences of the displacements of shells on the values of subsidence zones. The presence of a stiffening ring and a stationary roof provides the least values for vertical and horizontal displacements. Conclusions about the influence of the factors considered on the SSS of a tank in case of irregular subsidence of the external bottom contour are presented.
\end{abstract}

\section{Introduction}

Irregular subsidence of the external bottom contour is one of the reasons for the decrease in the operational reliability of the tank (Figure 1). Usually, destruction takes place in the welded seams of the bottom in the marginal zone and the junction of the wall with the bottom [1-7]. The question of the effect of irregular base subsidence on the stress-strain state of tanks has not been fully investigated, and the results sometimes contradict each other [8-11]. Figure 2 shows an example of inadmissible irregular subsidence of the external bottom contour of the RVS.

In [12], the author calculated the stress-strain state of the lower tank junction in case of irregular subsidence. For this, the LIRA software package was used. As it turned out later, the solution in the "elastic" setting, without considering the rigidity of the roof and the stiffening ring, caused serious errors in calculations.

We suggest considering the influence of the central part of the bottom, annular plate, stiffening rings, roof on the change in the stress-strain state of the tank in case of irregular subsidence. Earlier, the elements listed above were not considered in the calculation

* Corresponding author: alesya2010-11@yandex.ru 
schemes of most authors. In $[13,14]$, the adequacy of the proposed model was tested by solving a well-known analytic axisymmetric problem in a linear formulation. The results of the numerical solution realized in the ANSYS software and the analytical one differ by not more than $2 \%$, which indicates the possibility of using the proposed model for more complex calculations in a non-axisymmetric setting.

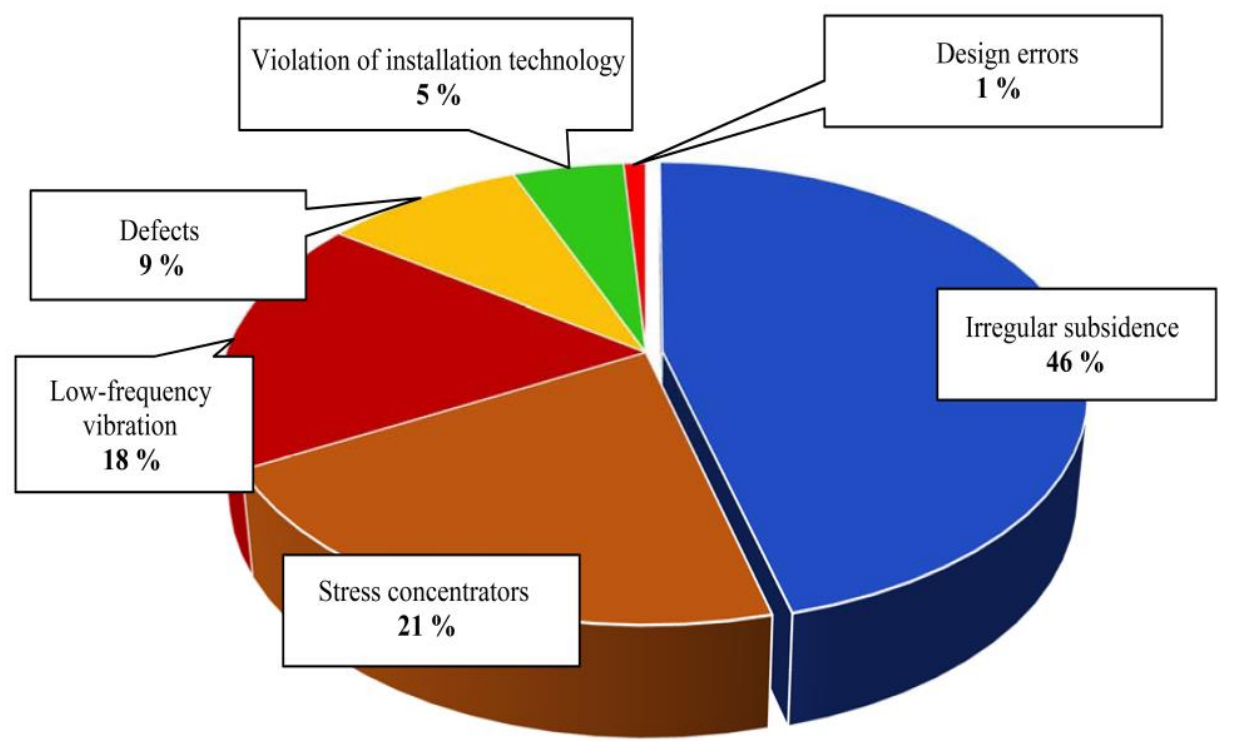

Fig. 1. Causes of vertical steel tanks accidents.

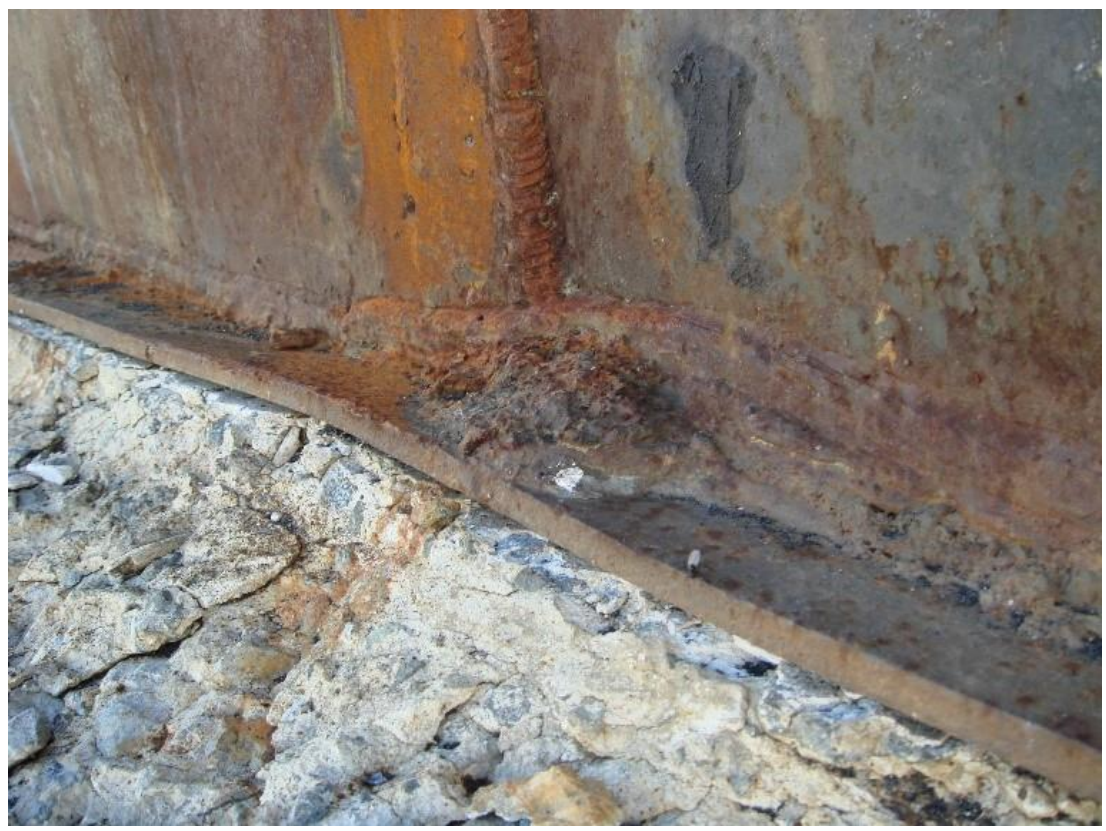

Fig. 2. Inadmissible irregular subsidence of the external bottom contour. 


\section{Methods}

The calculation model (Figure 3) includes the effect of the load from the weight of the stationary cover and equipment, the snow cover and the own weight of the tank wall.

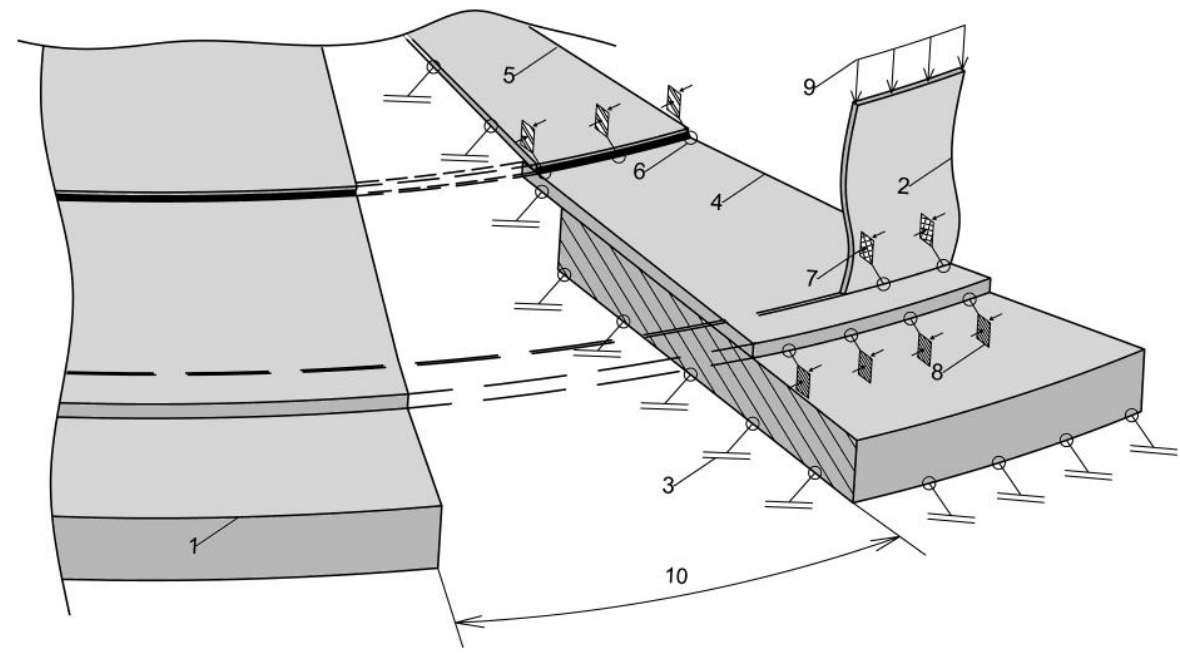

Fig. 3. Calculation model: 1 - ring foundation; 2 - wall; 3 - «elastic support»; 4 - annular plate; 5 central part of the bottom; 6 - contact of the annular plate and the central part of the bottom (manual contact region «surface body to surface body»); 7 - contact of the wall sheets and the annular plate (manual contact region «surface body to edge»); 8 - contact of the foundation ring and the annular plate (manual contact region «surface body to solid»); 9 - total load from the weight of the stationary cover and equipment, the snow cover and the own weight of the tank wall; 10 - arc size of the subsidence zone.

The foundation ring is absolutely rigid and rests on a base with a bed coefficient of 200 $\mathrm{MPa} / \mathrm{m}^{3}$. It is stated in [12] that the reinforced concrete foundation ring does not receive angular deformations with a change in the rigidity of the base, but only experiences a planeparallel vertical displacement.

Therefore, the choice of the bed coefficient does not affect the results of calculations within the proposed calculation scheme. Contact interaction requires the designation of a contact pair of surfaces or solids, where one of the objects is contact and the other is target. The contact zone of the foundation ring and the ground base, as well as the contact of the central part of the bottom and the base, is specified by the condition "elastic support". Contacts of the wall and the annular plate (manual contact region "surface body to edge"), the annular plate and the foundation ring (manual contact region "surface body to solid"), the annular plate and the central part of the bottom (manual contact region «surface body to surface body») are modeled by the final elements CONTA175 and TARGE170 [15-17].

A geometric model of the tank is constructed in accordance with the values adopted in the standard design for RVS-20000. The tank radius is $22.85 \mathrm{~m}$, the wall height is $11.92 \mathrm{~m}$. The wall thickness for the first belt is $13 \mathrm{~mm}$, for the $2-8$ belts $-11 \mathrm{~mm}$.

The wall sheets are aligned along the inner edge. In the proposed model, the wall, the annular plate, the bottom, and the stiffening ring are represented by shell finite elements SHELL181. Roofing is modeled by beam finite elements BEAM4 and consists of 48 Ibeams, profile I35B1 according to GOST 8239-89. The material of steel structures is lowalloyed structural steel $09 \mathrm{G} 2 \mathrm{~S}$ with a yield strength of $300 \mathrm{MPa}$.

Let us consider three cases of deformation of the RVS-20000 wall due to the action of loads caused by irregular subsidence of the foundation ring of the tank. In the first case, let 
us consider the deformation of the tank wall without a stiffening ring and a stationary roof. In the second - with a stiffening ring. In the third - with a fixed roof and a stiffening ring. The irregular tank subsidence is modeled by cutting out a segment of a foundation ring of size L (Figure 4).

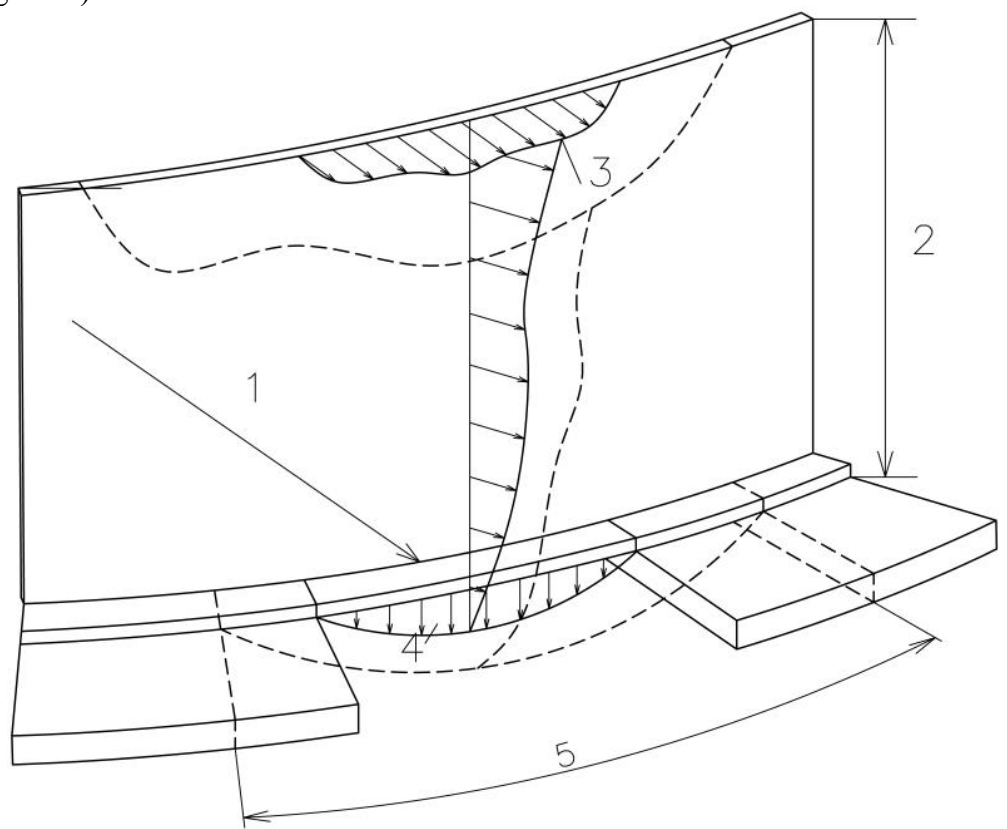

Fig. 4. Loading model: 1 - tank radius; 2 - tank height; 3 - radial wall displacements; 4 - vertical displacements of the wall and annular plate; 5 - arc size of the subsidence zone.

For convenience in presenting the results of calculations, it is proposed to use the dimensionless parameter $\mathrm{m}$ assumed in the theory of shells, which considers the size of the loading zone (tank subsidence):

$$
m=\frac{\pi \cdot R}{L}
$$

The experiment assumes the presence of two factors. The first factor is the geometric tank model with three combinations: without a stiffening ring and a fixed roof, with a stiffening ring and without a fixed roof, with a stiffening ring and a stationary roof. The second factor is the value of the coefficient $\mathrm{m}$.

\section{Results and discussion}

Figure 5 shows the stress diagram of the tank structures in the case of the model with a stiffening ring and a stationary roof. The zone of the largest displacement of the beams, which is above the subsidence zone, is indicated.

Table 1 presents the results of vertical and radial displacements of the tank wall in the three cases under study, as well as the maximum equivalent stresses. Without a stiffening ring and a fixed roof, the maximum deflections are $657 \mathrm{~mm}$ in the radial direction and $142.8 \mathrm{~mm}$ in the vertical direction.

When a stiffness ring is considered, the maximum values of radial deflections decrease by 60 times, and vertical ones - by 40 times. With a fixed roof and a stiffening ring, the values of radial deflections decrease by 120 times, and vertical ones - by 50 times, while 
relatively large displacements of the roof beams above the subsidence zone (up to $25 \mathrm{~mm}$ in the vertical direction) are observed.

The maximum radial displacements (and equivalent stresses) of the wall in all cases are attained at a maximum height of $\mathrm{h}=11.92 \mathrm{~m}$, the point of greatest deviation lying on the generatrix passing through the middle of the cut segment. The greatest vertical displacements are achieved in the corner weld joint in the middle of the cut segment.

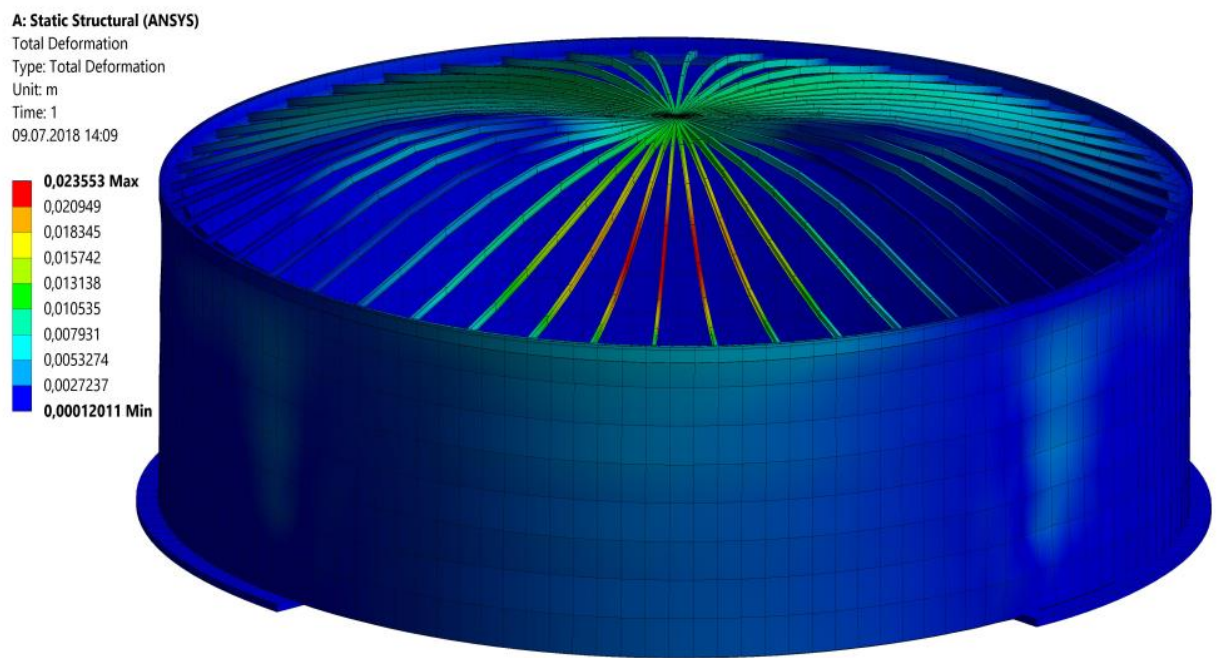

Fig. 3. Stress diagram of the tank structures.

Table 1. Results of calculations in the ANSYS software package.

\begin{tabular}{|c|c|c|c|c|}
\hline L, mm & $\mathrm{m}$ & $\mathrm{S}, \mathrm{mm}$ & $\mathrm{Q}, \mathrm{mm}$ & $\begin{array}{c}\text { Maximum equivalent } \\
\text { stresses, MPa }\end{array}$ \\
\hline \multicolumn{5}{|c|}{ With a stationary roof and a stiffening ring } \\
\hline 36000 & 2 & 3.26 & 5.68 & 28.8 \\
\hline 24000 & 3 & 1.58 & 3.49 & 23.68 \\
\hline 18000 & 4 & 1.04 & 2.43 & 20.32 \\
\hline 14000 & 5 & 0.65 & 1.87 & 17.13 \\
\hline 12000 & 6 & 0.59 & 1.72 & 16.6 \\
\hline \multicolumn{5}{|c|}{ With a stiffening ring and without a fixed roof } \\
\hline 36000 & 2 & 5.2 & 10.84 & 40.4 \\
\hline 24000 & 3 & 1.99 & 4.93 & 22.7 \\
\hline 18000 & 4 & 1.17 & 2.86 & 19.9 \\
\hline 14000 & 5 & 0.68 & 1.39 & 19.7 \\
\hline 12000 & 6 & 0.57 & 1.1 & 195.2 \\
\hline \multicolumn{7}{|c|}{ Without a stiffening ring and a fixed roof } \\
\hline 36000 & 2 & 142.8 & 595 & 88.4 \\
\hline 24000 & 3 & 84.7 & 657 & 26.9 \\
\hline 18000 & 4 & 29.5 & 369 & 134 \\
\hline 14000 & 5 & 8.24 & 93 & \\
\hline 12000 & 6 & 5.05 & \multicolumn{5}{|l|}{} \\
\hline
\end{tabular}




\section{Conclusions}

The article presents the results of calculating the SSS of a vertical steel tank in case of irregular subsidence of the external bottom contour, considering the stiffness of such structural elements as the stiffening ring, annular plate, central part of the bottom, and roof. The authors considered the physical and geometric nonlinearity of the model.

The presence of a stiffening ring and a stationary roof provides the least values for vertical and horizontal displacements. Thus, to obtain adequate results in calculating the influence of non-axisymmetric loads on the SSS of a tank, it is necessary to consider the above elements in the calculation model. The model proposed by the authors makes it possible to simulate various cases of irregular subsidence in a non-axisymmetric setting considering specific technical and operational conditions.

\section{Acknowledgments}

The paper was prepared within the implementation of the basic part of the government task for the project № 7.7858.2017/BP: "Development of the scientific principles of the techniques for determining the stress-strain state of the large-sized storage tanks during the differential settlement of the substructures and foundations".

\section{References}

1. P.V. Chepur, A.A. Tarasenko, A.A. Gruchenkova, J. of Phys.: Conf. Series 1015, 032049 (2018)

2. A. Tarasenko, A. Gruchenkova, P. Chepur, Proc. Eng. 165, 1125-1131 (2016)

3. A.A. Tarasenko, P.V. Chepur, S.V. Chirkov, Oil Indust. 3, 123-125 (2016)

4. A.A. Tarasenko, P.A. Konovalov, F.F. Zekhniev, P.V. Chepur, D.A. Tarasenko, Soil Mech. and Found. Eng. 53(6), 405-411 (2017)

5. A.A. Tarasenko, P.V. Chepur, Soil Mech. and Found. Eng. 53(4), 238-243 (2016)

6. A. Tarasenko, P. Chepur, A. Gruchenkova, MATEC Web of Conf. 73, 01018 (2016)

7. A. Tarasenko, P. Chepur, S. Chirkov, AIP Conf. Proc. 1772, 060010 (2016)

8. Y. Guan, A.A. Tarsenko, S. Huang, P.V. Chepur, R. Zhang, World Inf. on Earthquake Eng. 32(1), 219-227 (2016)

9. A.A. Tarasenko, P.V. Chepur, Y. Guan, Oil Indust. 4, 134-136 (2016)

10. A.A. Tarasenko, P.V. Chepur, A.A. Gruchenkova, J. of Phys.: Conf. Series 1015, 032047 (2018)

11. A.A. Tarasenko, M.N. Redutinskiy, P.V. Chepur, A.A. Gruchenkova, J. of Phys.: Conf. Series 1015, 032048 (2018)

12. A.S. Gorelov, Neodnorodnye gruntovye osnovaniya $i$ ikh vliyanie na rabotu vertikal'nykh stal'nykh rezervuarov (Nedra, Saint Petersburg, 2009)

13. A. Tarasenko, P. Chepur, A. Gruchenkova, AISC 692, 936-943 (2018)

14. S. Chirkov, A. Tarasenko, P. Chepur, IOP Conf. Series: Earth and Environ. Sci. 90, 012102 (2017) 